\title{
Chinese Shar-Pei
}

National Cancer Institute

\section{Source}

National Cancer Institute. Chinese Shar-Pei. NCI Thesaurus. Code C53850.

The Chinese Shar-Pei is a heavily wrinkled dog with a large head, though dogs with smaller heads and tighter looking skins do occur in this breed. Puppies have more wrinkles than adults. Shar-Peis slowly loose their wrinkles as they get older. There are three coat varieties: horse-coat and brush-coat and a rare bear-coat. The unusual horsecoat is rough to the touch, prickly and off-standing. The brush-coated variety has longer hair and a smoother feel. The coat on either variety can be up to one inch in length. Coat colors include all solid colors and sables. Height: 18-20 inches (46-51 cm.) Weight: 40-55 pounds (18-25 kg.) 